\title{
Comorbidity between enuresis and attention deficit hyperactivity disorder: a case-control study
}

\author{
Noran Abd-Elmoneim, Eman Elsheshtawy*, Mohamed Elsayed, Zeinab Gomaa and Mahmoud Elwasify
}

\begin{abstract}
Background: Although there is a strong association between enuresis and psychopathology, little is known about the prevalence of specific psychiatric disorders. We investigate the prevalence of attention-deficit/hyperactivity disorder (ADHD) in children with enuresis and study the impact on child behavior, self-esteem, and different EEG findings. A total number of one hundred 6 to 12 years old children diagnosed as functional enuresis taken from specialized university setting for enuresis at Mansoura Pediatric Outpatient Clinic, in which they could be subdivided into 2 groups after assessment of attention deficit hyperactivity disorder (ADHD); according to DSM-IV criteria, we also compare them with a third ADHD group taken from Mansoura Psychiatric Outpatient Clinic $n=40$ to match the co-morbid "enuresis with ADHD" group. All were subjected to a diagnostic interview conducted and completed with parents and developmental and family history as well, also they subjected to Conner's parent rating scale-93(CPRS-93), Rosenberg self-esteem assessment scale, and EEG examination.

Results: There was high prevalence of ADHD in our study with about $40 \%$ in children with enuresis especially who met the DSM-IV criteria of inattention attending a specialized setting for enuresis at Mansoura Pediatric Outpatient Clinic which is a tertiary setting where the older the children of enuresis, the higher the prevalence of ADHD, also there is a relationship between abnormal epileptiform discharge in EEG finding and enuresis as same as ADHD which became greatly increased in the children who had both disorders who was the most affected group as regard behavioral problems and lowered self-esteem levels.

Conclusions: The strong association between ADHD and enuresis suggests that the presence of enuresis should motivate diagnostic assessment of ADHD especially the inattentive subtype. Abnormal EEG finding in the form of generalized slow and sharp waves may be useful as a predictor for the presence of ADHD in children with enuresis. Also, the co-morbidity increases the negative impact on child behavior and self-esteem.
\end{abstract}

Keywords: Enuresis, ADHD, Children, Self-esteem, EEG

\section{Background}

The most common elimination disorder that affects children is enuresis, which could be defined as per International Children's Continence Society guidelines as incontinence while asleep in discreet episodes [1].

Etiology of enuresis is complex, it includes genetic, organic, psychological, and behavioral factors [2]. Many

* Correspondence: emanmady85@yahoo.com
Mansoura School of Medicine, Mansoura, Egypt authors observed connections between enuresis and sleep where EEG finding shows increased depth of sleep in children with enuresis. Bader noted that children with enuresis had signs of short EEG arousal before enuresis, while Safarinejad found that deep sleep may be the cause $[3,4]$.

There is an observed association between enuresis and psychopathology in children which is evidenced by an increase of co-morbid behavioral disorders in general and of attention-deficit hyperactivity disorder (ADHD)

\section{Springer Open}

(c) The Author(s). 2020 Open Access This article is licensed under a Creative Commons Attribution 4.0 International License, which permits use, sharing, adaptation, distribution and reproduction in any medium or format, as long as you give appropriate credit to the original author(s) and the source, provide a link to the Creative Commons licence, and indicate if changes were made. The images or other third party material in this article are included in the article's Creative Commons licence, unless indicated otherwise in a credit line to the material. If material is not included in the article's Creative Commons licence and your intended use is not permitted by statutory regulation or exceeds the permitted use, you will need to obtain permission directly from the copyright holder. To view a copy of this licence, visit http://creativecommons.org/licenses/by/4.0/. 
in particular [5, 6]. Studies support the link between enuresis and ADHD where an association between higher scores of ADHD in children having enuresis problems specially inattention $[7,8]$. On the other hand, children with ADHD have a higher incidence of enuresis [9].

Enuresis treatment is more difficult in combination with ADHD because of non-compliance. Lloyda B et al. used stimulants where it acts by decreasing sleep arousal threshold thus allowing the child with enuresis to awaken to prevent an enuresis [10].

In this study, we aimed to assess the problem of comorbidity between enuresis and ADHD through analysis of different socio-demographic variables together with associated EEG changes and to study effects of this comorbidity on self-esteem.

\section{Methods}

\section{Study design and setting}

A case-control study was conducted on children at the Outpatient Clinic of Mansoura Pediatric Hospital in a specialized setting for enuresis treatment every Thursday and Psychiatric Outpatient Clinics from June 2016 till December 2016. A convenient sample of children having functional enuresis who were drug naïve was taken after consent from children and their parents to join the study.

Cases of functional enuresis who met the inclusion criteria were 120, their ages range from 6 to 12 years old, 5 cases refused to enter the study while 15 cases were dropped out during the study due to living at remote areas. On the other hand, cases diagnosed as enuresis who met the inclusion criteria and completed the tools of the study were 100 . Both sexes were included, they were divided into 2 groups after assessment of attention deficit hyperactivity disorder (ADHD) according to DSM-IV criteria: first group, enuresis without ADHD $n$ $=60$ cases which was referred as enuresis only. This includes patients having functional enuresis with no ADHD symptoms, excluding those who have any ADHD symptoms; second group, enuresis with ADHD $n=40$ cases.

Exclusion criteria for both groups who have symptoms suggestive of mental retardation or another psychiatric disorder, or having organic or medical causes of enuresis as DM, spina bifida, diabetes insipidus, congenital anomalies of the bladder, and other organic causes.

A control group consists of 40 children diagnosed as ADHD (was similar to the number of enuresis with ADHD group) who were age and sex matched. They were chosen from children attending the Psychiatric Outpatient Clinic diagnosed as ADHD according to DSM-IV criteria. We excluded children with psychiatric comorbidity or having mental retardation, comorbid enuresis of any cause was also excluded.

\section{Tools}

A semi-structured interview to emphasize age, sex, residency, socioeconomic status, home atmosphere, family history, and developmental history was done by interviewing parents.

For all groups, the following were applied:

A. Assessment of socioeconomic class was assessed by a new scale made by updating and validation of Fahmy and EL-Sherbiny scale $[11,12]$. The scale includes 7 domains with a total score of 84, with a lower score indicating lower SES: education, occupation, family, family possessions, economic, home sanitation, and health care. The score was classified into very low, low, middle, and high levels, depending on the quartiles of the calculated score rather than a fixed point.

B. Complete physical examination

C. Psychometric assessment using:

1- Structured clinical interview for DSM-IV Axis I disorder KID-SCID scale diagnostic interview used to determine DSM-IV Axis I psychiatric disorders in children [13].

2- Conner's parent rating scales (CPRS-93) [14]: Arabic version was used [15].

3- The Rosenberg self-esteem scale: To assess selfesteem level in children and adolescents. The scale ranges from $0-30$. Scores between 15 and 25 are within normal range; scores below 15 suggest low self-esteem [16]. The Arabic version of the Rosenberg self-esteem scale used in this study was translated and validated through previous research made by Abdel-Khalek and Korayem [17].

\section{Electrophysiological assessment}

Electroencephalogram (EEG) examination was carried under standard condition using the 10-20 international electrode placement system, with hyperventilation (continuously for $3 \mathrm{~min}$ ) and photic stimulation as provocative techniques. This was done to exclude the presence of epilepsy comorbid or as a cause for enuresis.

\section{Statistical analysis}

Data were entered into the SPSS for Windows (version 15.0; SPSS Inc., Chicago, IL, USA) and were analyzed using descriptive and analytic analyses including frequencies, mean and standard deviations, percent, $t$ test, and chi-square test for comparison of quantitative and 
qualitative variables, respectively, $F$ test for comparison of 3 groups, logistic regression analysis was done.

\section{Results}

In Table 1, the 3 groups were cross matched regarding all socio-demographic variable except for age, where the 2nd group "enuresis with ADHD" were significantly older with statistical significance $P=0.009^{*}$. The family history of enuresis was statistically increased in the first and second groups (with or without ADHD) versus control group $P 2=0.003^{*}$, but no statistical difference between both groups of enuresis.

Table 2 shows that the group of enuresis with ADHD was more inattentive with a significant statistical difference, while the group of ADHD was more hyperactive $(P<0.001)$.

Regarding recorded EEG changes and self-esteem assessment as observed in Table 3, in the 1st group, there is a statistical significant increase of focal sharp waves in fronto-temporal region (52.2\%) versus the others. In enuresis with ADHD group, there is a statistical significant increase of generalized slow and sharp waves (39.3\%). While in the control group, there is a statistical significant increase of focal sharp waves in the temporal region mainly in the left side $(62.5 \%)$ versus the other groups. No difference is observed between both groups of enuresis either with or without ADHD as regard self-esteem scores. In enuresis with ADHD group (70.0\%) shows low self-esteem with significant statistical difference $P 3=0.01$.

Regarding Table 4, there is a significant statistical difference between the 3 groups regarding most of the subscales of Conner's except in the restless-disorganized subscale. The enuresis only group, anxious-shy, and psycho-somatic subscales is higher with a mean of 67.5 \pm 10.6 , while in ADHD group, there is a statistical increase of learning problems subscale with mean of $62.9 \pm 12.9$.

Table 5 shows the results of logistic regression where EEG abnormality specially generalized waves was the only predictor for presence of ADHD in children with enuresis.

\section{Discussion}

In our study, we traced the association between enuresis and ADHD in children from 6 to 12 years taken from Mansoura University Pediatric and Psychiatric Outpatient Clinic. The number of cases complaining of enuresis was 100,40 of them were found to have symptoms of ADHD with a prevalence rate of $40 \%$. This high rate of ADHD in our study because most resistant and problematic cases are usually referred to university hospitals, which is a tertiary care unite. This was very similar to the previous conducted studies $[2,8]$. They explained that the association between both enuresis and inattentive ADHD subtype

Table 1 Socio-demographic characteristics of the 3 studied groups

\begin{tabular}{|c|c|c|c|c|c|}
\hline & $\begin{array}{l}\text { Enuresis only } \\
(n=60)\end{array}$ & $\begin{array}{l}\text { Enuresis with ADHD } \\
(n=40)\end{array}$ & ADHD control $(n=40)$ & Sig. test & $P$ value \\
\hline Age & $8.5 \pm 1.8$ & $9.6 \pm 1.8$ & $8.5 \pm 1.9$ & $F=4.84$ & $\begin{array}{l}0.009^{*} \\
\text { LSD: } 2 \text { vs } 1.3\end{array}$ \\
\hline \multicolumn{6}{|l|}{ Sex } \\
\hline Male & $42(70.0)$ & $27(67.5)$ & $28(70.0)$ & \multirow{2}{*}{$\begin{array}{l}x^{2}=0.07 \\
x^{2}=0.0 \\
x^{2}=0.06\end{array}$} & \multirow{2}{*}{$\begin{array}{l}P 1=0.79 \\
P 2=1.0 \\
P 3=0.81\end{array}$} \\
\hline Female & $18(30.0)$ & $13(32.5)$ & $12(30.0)$ & & \\
\hline \multicolumn{6}{|l|}{ Residence } \\
\hline Rural & $41(68.3)$ & $31(77.5)$ & $29(72.5)$ & \multirow{2}{*}{$\begin{array}{l}x^{2}=1.00 \\
x^{2}=0.19 \\
x^{2}=0.27\end{array}$} & \multirow{2}{*}{$\begin{array}{l}P 1=0.32 \\
P 2=0.66 \\
P 3=0.61\end{array}$} \\
\hline Urban & $19(31.7)$ & $9(22.5)$ & $11(27.5)$ & & \\
\hline \multicolumn{6}{|l|}{ SES } \\
\hline Very low & $10(16.7)$ & $10(25.0)$ & $10(25.0)$ & \multirow[t]{4}{*}{ Fisher's exact test } & \multirow{4}{*}{$\begin{array}{l}P 1=0.78 \\
P 2=0.66 \\
P 3=0.95\end{array}$} \\
\hline Low & $33(55.0)$ & $20(50.0)$ & $22(55.0)$ & & \\
\hline Middle & $14(23.3)$ & $8(20.0)$ & $6(15.0)$ & & \\
\hline High & $3(5.0)$ & $2(5.0)$ & $2(5.0)$ & & \\
\hline Family history of enuresis & $23(38.3)$ & $14(35.0)$ & $4(10.0)$ & $x^{2}=0.06$ & $\begin{array}{l}P 1=0.81 \\
P 2=0.003^{*} \\
P 3=0.003^{*}\end{array}$ \\
\hline Family history of epilepsy & $3(5.0)$ & $4(10.0)$ & $2(5.0)$ & Fisher's exact test & $\begin{array}{l}P 1=0.26 \\
P 2=0.74 \\
P 3=0.17\end{array}$ \\
\hline
\end{tabular}

* significant $p<0.01$ 
Table 2 Distribution of ADHD subtypes in relation to enuresis

\begin{tabular}{|c|c|c|c|c|}
\hline \multirow[t]{2}{*}{$\begin{array}{l}\text { Clinical } \\
\text { subtypes }\end{array}$} & $\begin{array}{l}\text { Enuresis e ADHD group } \\
(n=40)\end{array}$ & $\begin{array}{l}\text { ADHD group } \\
(n=40)\end{array}$ & \multirow[t]{2}{*}{$\begin{array}{l}\text { Sig. } \\
\text { test }\end{array}$} & \multirow[t]{2}{*}{$P$ value } \\
\hline & No. (\%) & No. (\%) & & \\
\hline Inattentive & $24(60.0)$ & $10(25.0)$ & \multirow[t]{3}{*}{ FET } & \multirow[t]{3}{*}{$P<0.001^{*}$} \\
\hline Hyperactive & $2(5.0)$ & $14(35.0)$ & & \\
\hline Combined & $14(35.0)$ & $16(40.0)$ & & \\
\hline
\end{tabular}

* Significant at $P<0.01$ highly significant

may be due to a deficits in arousal. Other studies reported that the rate ranges from 10 to $20 \%$, which may be due to differences in the sampling method or due to different age groups $[18,19]$.

Our data also revealed that the older the children, the higher the prevalence of the ADHD, this finding reflects the potential importance of ADHD as a comorbidity factor in a therapy resistant population and indicate the importance of screening and early treatment of ADHD. This was similar to a study made by Bayens who found the maximal prevalence of enuresis at age of 8 years, followed by a decline to age 11 years which was consistent with the findings that the older the children, the higher the prevalence of the ADHD [5].

By studying gender disparity between the groups in our study, there was a male predominance with about 2 : 1 male to female ratio. This data is in concordance with a study of Tai HL, Sheerman $[6,20]$. Where ADHD is similar to enuresis, as in each disorder, boys are generally more often than girls. Thus, the chance for boys having enuresis to have increased behavioral problems is twice as high as for girls with enuresis. This was similar to an epidemiological study in Moroccan children [21].

Socio-economic level revealed that most of children of the 3 groups had mainly very low or low scores, as they were coming mostly from rural areas. This was similar to a study of Beiderman J who reported that enuresis is strongly associated with social disadvantage, as psychopathology such as ADHD [22]. It has been postulated that socioeconomic status (SES) is a common underlying factor by which behavioral problems and enuresis emerge simultaneously [23].

Other risk factors of enuresis include family history of enuresis which is similar to studies of Bayoumi RA and Wang QW $[24,25]$. Considering the family history of enuresis in a study by Ismail et al., more than fifty of children of enuresis had a positive family history, which was explained by presence of genetic factor in occurrence of enuresis; however, this result was slightly higher than our study, as family history involved only the first-degree relatives [18].

EEG (electro-encephalography) was done to confirm the underlying pathology in each group. Enuresis with

Table 3 EEG, self-esteem assessment of the three studied groups

\begin{tabular}{|c|c|c|c|c|c|}
\hline \multirow[t]{2}{*}{ EEG findings } & $\begin{array}{l}\text { Enuresis only group } \\
(n=60)\end{array}$ & $\begin{array}{l}\text { Enuresis e ADHD group } \\
(n=40)\end{array}$ & $\begin{array}{l}\text { ADHD group } \\
(n=40)\end{array}$ & \multirow[t]{2}{*}{ Sig. test } & \multirow[t]{2}{*}{$P$ value } \\
\hline & No. (\%) & No. (\%) & No. (\%) & & \\
\hline$\overline{\text { Normal }}$ & $37(61.7)$ & $12(30.0)$ & $16(40.0)$ & \multirow{2}{*}{$\begin{array}{l}X^{2} 1=9.6 X^{2} 2=4.5 \\
X^{2} 3=0.88\end{array}$} & \multirow{2}{*}{$\begin{array}{l}P 1=0.002^{*} \\
P 2=0.03^{*} P 3=0.35\end{array}$} \\
\hline Abnormal & $23(38.3)$ & $28(70.0)$ & $24(60.0)$ & & \\
\hline \multirow[t]{3}{*}{ Type of abnormality } & $\begin{array}{l}\text { Generalized sharp } \\
\text { and slow waves }\end{array}$ & $2(8.7)$ & $11(39.3)$ & $6(25.0)$ & \multirow{3}{*}{$\begin{array}{l}P 1=0.04^{*} \\
P 2=0.01^{*} \\
P 3=0.02^{*}\end{array}$} \\
\hline & $\begin{array}{l}\text { Focal sharp and slow } \\
\text { waves in temporal region }\end{array}$ & $9(39.1)$ & $7(25.0)$ & $15(62.5)$ & \\
\hline & $\begin{array}{l}\text { Focal sharp and slow } \\
\text { waves in fronto-temporal } \\
\text { region }\end{array}$ & $12(52.2)$ & $10(35.7)$ & $3(12.5)$ & \\
\hline \multicolumn{4}{|l|}{ Self-esteem } & Fisher's exact test & \multirow{4}{*}{$\begin{array}{l}P 1=0.49 \\
P 2=0.08 \\
P 3=0.008^{*}\end{array}$} \\
\hline Low (0-15) & $36(60.0)$ & $28(70.0)$ & $15(37.5)$ & & \\
\hline Average (15-25) & $20(33.3)$ & $11(27.5)$ & $20(50.0)$ & & \\
\hline High (25-30) & $4(6.7)$ & $1(2.5)$ & $5(12.5)$ & & \\
\hline
\end{tabular}

$P 1$ statistical significant difference between enuresis only and enuresis with ADHD group, $P 2$ statistical significant difference between enuresis only and control group, $P 3$ statistical significant difference between enuresis with ADHD and control group $X^{2}=$ chi-square test

* significant at $p$ value $<0.05$ 
Table 4 Comparison between Conners' parent rating scale (CPRS-93) of the 3 studied groups

\begin{tabular}{|c|c|c|c|c|c|c|}
\hline \multirow[t]{2}{*}{ Conner scale } & \multirow{2}{*}{$\begin{array}{l}\text { Enuresis only group } \\
(n=60) \\
\text { Mean ( } \square \mathrm{SD})\end{array}$} & \multirow{2}{*}{$\begin{array}{l}\text { Enuresis e ADHD group } \\
(n=40) \\
\text { Mean ( } \square \text { SD) }\end{array}$} & $\begin{array}{l}\text { ADHD group } \\
(n=40)\end{array}$ & \multirow[t]{2}{*}{ Sig. test } & \multirow[t]{2}{*}{$P$ value } & \multirow[t]{2}{*}{ LSD } \\
\hline & & & Mean ( $\square$ SD) & & & \\
\hline Conduct & $44.3(12.2)$ & $60.3(12.2)$ & $53.4(9.9)$ & $F=23.6$ & $0.001^{*}$ & 2 vs 1.3 \\
\hline Anxious-shy & $67.5(10.6)$ & $59.2(13.2)$ & $40.3(11.1)$ & $F=67.1$ & $0.001^{*}$ & 1 vs 2.3 \\
\hline Restless disorganized & $61.8(11.7)$ & $57.1(10.3)$ & $59.7(13.2)$ & $F=1.9$ & 0.15 & \\
\hline Learning disability & $52.6(6.9)$ & $62.4(11.5)$ & $62.9(12.9)$ & $F=16.3$ & $0.001^{*}$ & 2.3 vs 1 \\
\hline Psychosomatic & $69.7(8.1)$ & $63.4(12.3)$ & $30.2(1.4)$ & $F=275.5$ & $0.001^{*}$ & 1 vs 2.3 \\
\hline Obsessive compulsive & $33.1(6.9)$ & $47.9(7.01)$ & $30.0(0.0)$ & $F=108.2$ & $0.001^{*}$ & 2 vs 1.3 \\
\hline Antisocial & $34.8(7.9)$ & $59.7(12.7)$ & $51.9(5.6)$ & $F=100.3$ & $0.001^{*}$ & 2 vs 1.3 \\
\hline Hyperactivity immature & $33.3(7.7)$ & $64.6(15.3)$ & $52.5(16.6)$ & $F=72.3$ & $0.001^{*}$ & 2 vs 1.3 \\
\hline Hyperactivity index & $32.9(5.9)$ & $61.2(13.6)$ & $53.0(13.4)$ & $F=90.9$ & $0.001^{*}$ & 2 vs 1.3 \\
\hline
\end{tabular}

significant $P 1$ statistical significant difference between enuresis only and enuresis with ADHD group, $P 2$ statistical significant difference between enuresis only and control group, $P 3$ statistical significant difference between enuresis with ADHD and control group

*highly significant $P<.01$

ADHD group had an association between EEG abnormalities with a family history of enuresis, in which generalized slow and sharp waves in EEG finding is statistically significant. These were found to be a predictor for presence of co-morbid ADHD diagnosis in children with enuresis by logistic regression analysis.

Enuresis only group showed high incidence of focal slow or sharp waves in fronto-temporal region, while focal sharp waves in the temporal region were found mostly in the ADHD control group, these findings were mainly on the left side. These results were supported by a study, which found that most cases of children who presented with attention deficit hyperactivity disorder, enuresis, and breath-holding spells had abnormal generalized or focal sharp waves predominantly in the left hemisphere in most patients [26]. This suggests that epileptiform activity in non-epileptic children might reflect age-dependent mechanisms of brain dysfunction. It is possible that global CNS maturation delay may be a contributor to enuresis. This was proved by Hunsballe $\mathrm{JM}$, who noticed that progressive maturation of bladder stability occurs in conjunction with EEG findings suggest increased CNS recognition of bladder fullness and the

Table 5 Stepwise Logistic regression analysis of risk factors between enuresis only group and enuresis with ADHD group

\begin{tabular}{|c|c|c|c|}
\hline Risk factors & $\square$ & $P$ & OR $(95 \% \mathrm{Cl})$ \\
\hline \multicolumn{4}{|l|}{ EEG } \\
\hline Generalized & 2.8 & $0.001^{*}$ & $16.9(3.3-87.5)$ \\
\hline Focal in bitemporal region & 0.88 & 0.15 & $2.39(0.74-7.8)$ \\
\hline Focal in frontotemporal & 0.94 & 0.08 & $2.6(0.89-7.4)$ \\
\hline Constant & & & -1.13 \\
\hline Model $x^{2}$ & & & $16.6, p \leq 0.001^{*}$ \\
\hline$\%$ predicted & & & 69.0 \\
\hline
\end{tabular}

** highly significant $p<.001$ ability to suppress the onset of bladder contraction, which improves with increasing of age [27]. The same was reported in study by Hashem S, while it was contradicted by study of Morohongo et al. who found that only half of the children with ADHD had abnormal epileptiform discharges in EEG findings [28, 29].

It was found that the co-morbidity between enuresis and ADHD worsen the self-esteem level, although there was no statistical difference between both groups of enuresis which means that enuresis had its own negative impact on self-esteem regardless of the ADHD diagnosis. This was supported by a previous study of Mellon MW et al. [9].

Regarding the impact of enuresis and ADHD on children's behavior, "enuresis only" group showed only a significant increase in anxious-shy and psycho-somatic subscales, which can be explained by feeling of shame due to fear from being discovered by others, which makes the child distressed and shy. While in the control ADHD group, there is a statistical increase of learning disability. This could be explained by presence of ADHD diagnosis, in which the core symptoms of inattention, hyperactivity, and impulsivity have a direct negative impact on the learning process.

In this study, it was clear that enuresis with ADHD showed higher levels of behavioral problems and lower levels in self-esteem scores.

\section{Conclusions}

- Prevalence of ADHD in a child having enuresis reached about $40 \%$ which requires careful assessment and management of the symptoms of $\mathrm{ADHD}$ that rarely receive treatment. The presence of enuresis in a child causes a psychological and 
social embarrassment leading to low self-esteem and behavioral problems on rating scales. While the association between enuresis and EEG changes in a child can predict the presence of comorbid ADHD. We recommend the following:

- Further developmental, genetic, and family studies are recommended to verify the link between both disorders.

- Quantitative EEG techniques or sleep EEG assessment to illustrate the relationship between sleep disorders or arousal problems and enuresis as well as ADHD.

- Assessment of ADHD should routinely include evaluation for enuresis and vice versa through collaboration between psychiatrists, pediatric health care professionals, general practitioners, and school mental health team together with parents aiming at achieving better health care.

\section{Limitations}

Our study did not give a specific explanation for enuresis and ADHD through EEG but it could give an idea about association of enuresis with ADHD and different EEG findings. Also, a small number of the sample would limit the generalizability of the results, thus including higher number of subjects would increase statistical power.

\section{Abbreviations}

ADHD: Attention deficit hyperactivity disorder; EEG: Electroencephalogram; DSM: Diagnostic and statistical manual

\section{Acknowledgements}

Not applicable

\section{Authors' contributions}

$\mathrm{N}$ A interviewed cases, applied scales, and interpretation of data. E E corresponding author, design the work and revised the manuscript. M E wrote the manuscript, statistical analysis, and interpretation. Z G gave the idea of the research. M E designed the work and interpreted data. The authors read and approved the final manuscript.

\section{Funding}

No fund was received

\section{Availability of data and materials}

The datasets used and/or analyzed during the current study are available from the corresponding author on reasonable request.

\section{Ethics approval and consent to participate}

We conducted the study after obtaining approval from the Research Committee of the Psychiatric Department at Mansoura University.

- Informed consent was obtained from parents after an explanation of the aim and procedures of the study.

- All precautions were taken to maintain the privacy of the data.

\section{Consent for publication}

Not applicable

\section{Competing interests}

The authors declare that they have no competing interests.
Received: 14 May 2020 Accepted: 12 June 2020

Published online: 07 August 2020

\section{References}

1. Neveus T, von Gontard A, Hoebeke P, Hjalmas K, Bauer S, Bower W, Djurhuus JC (2006) The standardization of terminology of lower urinary tract function in children and adolescents: report from the standardisation committee of the International Children's Continence Society. J Urol 176: 314-324

2. Baeyens D, Roeyers H, Hoebeke P, Verté S, Van Hoecke E, Vande Walle J (2004) Attention-deficit/hyperactivity disorder in children with nocturnal enuresis. J Urol 171:2576-2579

3. Bader G, Nevéus T, Kruse S, Sillén U (2002) Sleep of primary enuretic children and controls. Sleep 25:579-583

4. Safarinejad MR (2007) Prevalence of nocturnal enuresis, risk factors, associated familial factors and urinary pathology among school children in Iran. J Pediatr Urol 3(6):443-452

5. Baeyens D, Roeyers H, Vande Walle J, Hoebeke P (2005) Behavioural problems and attention deficit-hyperactivity disorder in children with enuresis: a literature review. Eur J Pediatr 164:665-672

6. Shreeram S, He J, Kalaydjian A, Brothers S, Merikangas KR (2009) Prevalence of enuresis and its association with attention-deficit/hyperactivity disorder among U.S. children: results from a nationally representative study. J Am Acad Child Adolesc Psychiatry 48(1):35-41

7. Baeyens D, Roeyers H, Hoebeke P, Antrop I, Mauel R, Vande Walle J (2006) The impact of attention deficit hyperactivity disorders on brainstem dysfunction in nocturnal enuresis. J Urol 176:744-748

8. Elia J, Takeda T, Deberardinis R, Burke J, Aacardo J, Ambrosini PJ, Blum NJ, Brown LW, Lantieri F, Berrenttini W, Devoto M, Hakonarson H (2009) Nocturnal enuresis: a suggestive endophenotype marker for a subgroup of inattentive attention-deficit/hyperactivity disorder. J Pediatr 155(2): 239-244.e5

9. Mellon MW, Natchev BE, Katusic SK, Colligan RC, Weaver AL, Voigt RG, Barbaresi WJ (2013) Incidence of enuresis and encopresis among children with attention-deficit/hyperactivity disorder in a population-based birth cohort. Acad Pediatr 13(4):322-327. https://doi.org/10.1016/j.acap.2013

10. Lloyda B, Williamson M, Gower M, Ulzen T (2011) Enuresis and ADHD in older children and an adolescent treated with stimulant medication: a case series. J Can Acad Child Adolesc Psychiatry 20:1

11. Fahmy S, El-Sherbini AF (1983) Determining simple parameters for social classifications for health research. Bull High Inst Public Health 13:95-108

12. El-Gilany A, El-Wehady M, El-Wasify M (2012) Updating and validation of the socioeconomic status scale for health research in Egypt. East Mediterr Health J 18:962

13. Hien D, Matzner F, First M, Spitzer R, Williams J, Gibbon M (2004) Structured clinical interview for DSM IV childhood diagnoses. KID - SCID

14. Conners CK (1989) symptom pattern in hyperkinetic, neurotic and normal children. Child Dev 41:667-682

15. Al-behairy AA (2011) Arabic version of Conner's parent rating scales for children and adolescent. Anglo, Cairo

16. Rosenberg M (1965) Society and the adolescent self-image, vol 110 Wesleyan univer Press, Middletown, pp 297-303

17. Abdel-KhaleK AM, Korayem AS (2007) Self-esteem among schools students from four Arabic countries. Psychol Rep 110:297-303

18. Ismail A, Abdelbasser K, Abdel-moniem M (2013) Prevalence and risk factors of PNE in school children in Qena Governate-EGYPT. Egyptian J Neurol Psychiatr AP 50:163-169

19. Mubarak AA, Elsawy HE, Seleem MA, Abdel-wahab DM (2016) Self-concept and psychiatric comorbidity in a sample of Egyptian adolescent with secondary nocturnal enuresis. Egypt J Psychiatric 37:17-24

20. Tai HL, Chang YJ, Chang SC, Chen GD, Chang CP, Chou MC (2007) The epidemiology and factors associated with nocturnal enuresis and its severity in primary school children in Taiwan. Acta Paediatr 96:242-245

21. Bourquia A, Chihabeddine K (2002) Enuresis: epidemiological study in Moroccan children. Saudi J Kidney Dis Transpl 13:151-154

22. Biederman J, Faraone SV, Monuteaux MC (2002) Differential effect of environmental adversity by gender: Rutter's index of adversity in a group of boys and girls with and without ADHD. Am J Psychiatry 158:1556-1562

23. Taylor E, Dopfner M, Sergeant J, Asherson P, Banaschewski T, Buitelaar J (2004) European guidelines for hyperkinetic disorder, first upgrade. Eur Child Adolesc Psychiatry 13:17-30 
24. Bayoumi RA, Eapen V, Al-Yahyaee S, Al Barwani HS, Hill RS, Al Gazali I (2006) The genetic basis of inherited primary nocturnal enuresis: a UAE study. J Psychosom Res 61:317-320

25. Wang QW, Wen JG, Song DK et al (2007) Bed-wetting in Chinese children: epidemiology and predictive factors. Neurourol Urodyn 26:512-517

26. Nogovitsyn VI, Nesterovskiĭ IE, Osipova GN, Rusakova VD, Mykhin KI (2011) Epileptiform activity in nonepileptic children: clinicalelectroencephalographic correlations, Article in Russian

27. Hunsballe JM (2000) Increased delta component in computerized sleep electroencephalographic analysis suggests abnormally deep sleep in primarily monosymptomatic nocturnal enuresis. Scand J Urol Nephrol 34(5):294-302

28. Hashem S, Salem S, El-Ghoneimy S, Mostafa SH, Nada M, Farouk A (2005) Neurophysiological assessment of the patients of primary nocturnal enuresis. Egypt J 42:301-309

29. Morohongo M-c, Iruma G (2014) Reappraisal of abnormal EEG findings in children with ADHD. Department of Neuropsychiatry and Psychosomatic Internal Medicine. Epilepsy Behav 41:251-256

\section{Publisher's Note}

Springer Nature remains neutral with regard to jurisdictional claims in published maps and institutional affiliations.

\section{Submit your manuscript to a SpringerOpen ${ }^{\circ}$ journal and benefit from:}

- Convenient online submission

- Rigorous peer review

- Open access: articles freely available online

- High visibility within the field

- Retaining the copyright to your article

Submit your next manuscript at $\boldsymbol{\triangleright}$ springeropen.com 